\title{
Uma reavaliação dos espaços teatrais das vanguardas em Event-space: theatre architecture and the historical avant-garde, de Dorita Hannah
}

\author{
Evelyn Furquim Werneck Lima \\ Universidade Federal do Estado do Rio de Janeiro
}

\section{Resumo}

Resenha de um ousado livro de Dorita Hannah, intitulado Event-Space: Theatre Architecture and the Historical Avant-Garde ("Evento-Espaço: Arquitetura Teatral e as vanguardas históricas"). A autora é uma das reconhecidas autoridades nas transformações recentes do Desenho da Performance e do espaço teatral e introduz novos conceitos espaciais fundamentados em Artaud e Bataille que são de grande interesse para a arte contemporânea.

Palavras-chave: Arte contemporânea. Arquitetura teatral. Performance.

Poucos arquitetos publicaram especificamente teorias sobre a construção de teatro no Ocidente. Em relação à historiografia da arquitetura teatral, os principais trabalhos disponíveis são livros de teóricos do teatro, como Places of Performance (1989) de Marvin Carlson e também as conferências deste autor sobre The Changing Places of Performance (2012, 2017), que atualizam os conceitos da obra anterior para o século XXI e A Short History of Western Performance Space (2003) de David Wiles, abrangendo desde os teatros da Grécia Antiga até os "found spaces" do século XX. Para ampliar esta ainda insipiente bibliografia, o novo livro de Dorita Hannah Event-Space: Theatre Architecture and the Historical AvantGarde - publicado pela Routledge e lançado em julho de 2018 - traz uma contribuição bem fundamentada e original ao campo de estudos específicos sobre arquitetura e performance teatral.

Com foco no espaço performático e na performatividade espacial, o novo livro de Hannah está na convergência entre teoria da arquitetura (discurso espacial) e teoria da performance (discurso dos acontecimentos), visando rever a crise do século XX quando o edifício teatral deixou de ser indispensável e diretores procuraram espaços menos convencionais.

Hannah identifica três atitudes para o espaço de performance que surgiram entre 1872 e 1947, chamando-as de Absolute, Abstracte Abject, em correspondência com o Simbolismo, 
Construtivismo e Surrealismo. À medida que os simbolistas, construtivistas e surrealistas da vanguarda histórica começaram a abandonar os espaços teatrais tradicionais, que já não correspondiam ao novo teatro e às conquistas tecnológicas, essas atitudes levaram a locais mais imprevisíveis para eventos teatrais e políticos, de modo que o ambiente construído para a performance se tornou não apenas parte do evento, mas um evento em si. O livro EventSpace examina vários modelos espaço-temporais que expressam essa revolução, iluminando a história da performance vanguardista e inspirando abordagens contemporâneas sobre o espaço para a performance.

Tendo lecionado arquitetura e design há mais de 25 anos, Dorita Hannah é Professora do Curso de Pesquisa Interdisciplinar de Arquitetura, Arte e Design na Universidade da Tasmânia (UTAS) e Professora Adjunta de Palco \& Espaço na Aalto University, Finlândia. Ela liderou muitas iniciativas internacionais, como Curadora de Pesquisa da Cenografia Mundial (WSD 2013), Curadora de Teoria da Quadrienal de Praga (PQ 2015) e Co-Curadora de Estados Fluidos (PSi 2015). Ela ganhou os prêmios New Zealand Architecture Awards do Designer Institute of New Zealand, bem como as medalhas Laureate da UNESCO (1999) e World Stage Design (2009). Atualmente é co-presidente do Grupo de Trabalho de Desenho da Cena da PSi e co-coordenadora do Grupo de Trabalho de Arquitetura e Teatro da Federação Internacional de Pesquisa Teatral-IFTR. Finalmente, ela é autora de inúmeros artigos sobre arquitetura teatral e co-editora de vários livros. Seu detalhado e brilhante domínio na área fortalece o argumento essencial do livro, baseado em sólida pesquisa e muito conhecimento.

Refletindo sua vasta experiência em uma análise coerente, este livro é resultado de uma acurada pesquisa histórica além de investigações e levantamentos realizados em campo. Hannah expõe um estudo detalhado dos espaços teatrais e de sua participação ativa nos espetáculos que sustentam a proposta teórica. Para o livro, ela trabalhou em parceria com o fotógrafo Marc Goodwin, que tirou fotos bem selecionadas dos edifícios analisados para ilustrar o livro e elucidar o argumento.

O livro está organizado em quatro capítulos, cada um correspondendo a um período histórico iniciado com a inauguração do teatro de Wagner em 1872 e funcionando até os tempos contemporâneos. O referencial teórico fundamenta-se na discussão de Friedrich Nietzsche sobre o encontro criativo e poderoso entre as forças de Apolo e Dionísio (2008 [1872]). O primeiro capítulo "Disciplinando a gloriosa máquina burguesa" demonstra o esgotamento do modelo do teatro de palco italiano, no qual o arco de proscênio separa o público dos atores. Neste capítulo, Hannah examina o Festspielhaus em Bayreuth (figura 1) como um exemplo da conclusão de uma era e da Opéra Garnier como uma apoteose entre o espetáculo e a vigilância com seus luxuosos foyers destinados ao evento da integração social (fig. 2). 


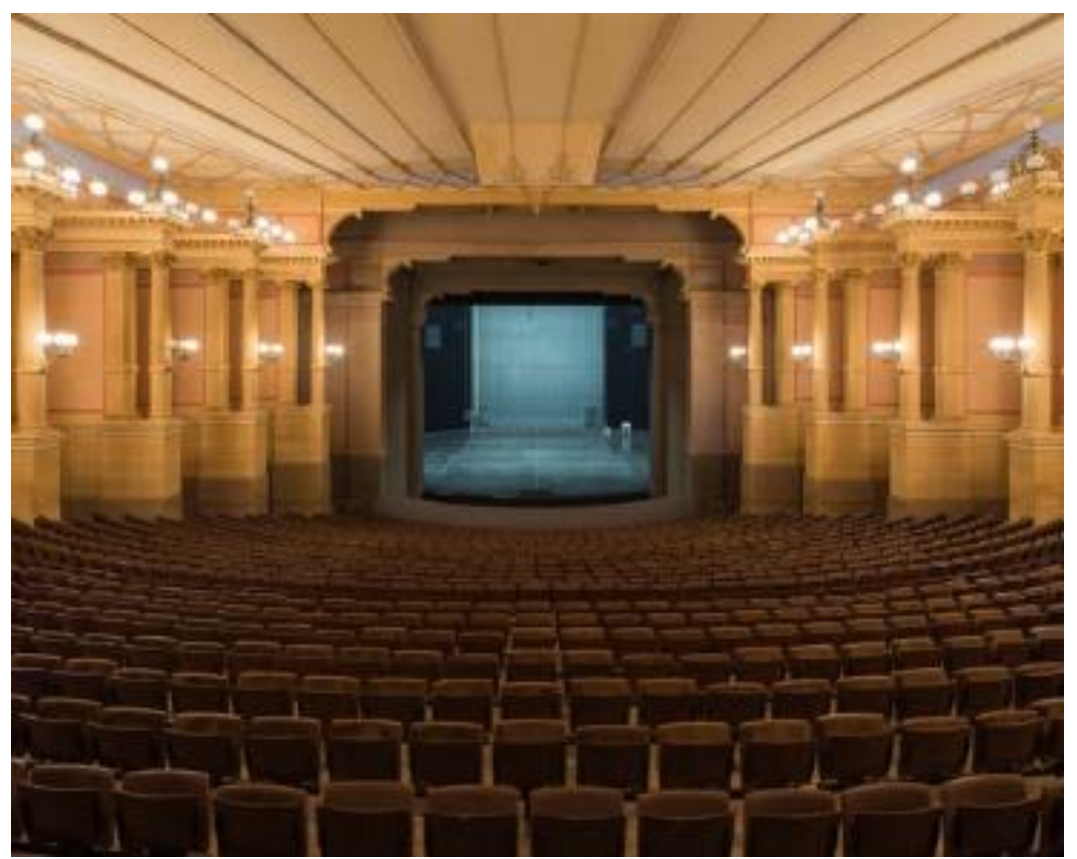

Figura 1. O Festspielhaus de Richard Wagner, construído por Otto Bruckwald, inspirado nos projetos não realizados de Gottfried Semper. Bayreuth, Alemanha. 1876. Cortesia do fotógrafo Marc Goodwin, 2014.

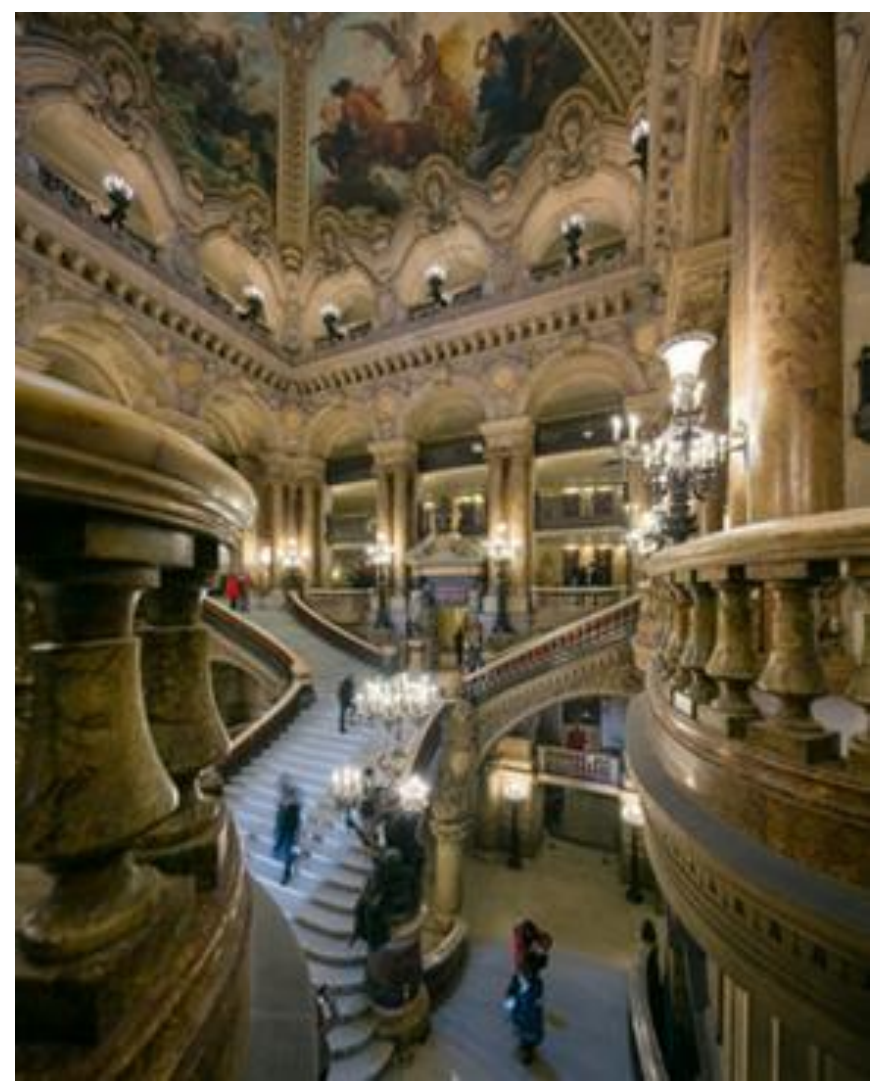

Figura 2. A Ópera Garnier, projetada por Charles Garnier, Paris, 1875.

Hannah considera os inúmeros foyers como "a maior oportunidade para apresentar sua arquitetura como um evento-espaço para múltiplos roteiros" (p. 73). Cortesia do fotógrafo Marc Goodwin, 2014. 
Os próximos três capítulos enfocam, separadamente, os três modelos espaciais identificados por Hannah. No capítulo 2, intitulado "Espaço absoluto: paisagens universais", a autora explora as paisagens atmosféricas e universais dos cenógrafos Edward Gordon Craig e Adolphe Appia (fig. 3). Ela argumenta que a cena proposta por Craig, inspirada no simbolismo do final do século XIX, ecoou nas propostas cenográficas de Appia reinterpretadas no último quartel do século XX pelo Teatro de Imagens de Robert Wilson e pelo espaço vazio de Peter Brook, em especial no Bouffes du Nord em Paris (fig. 4).

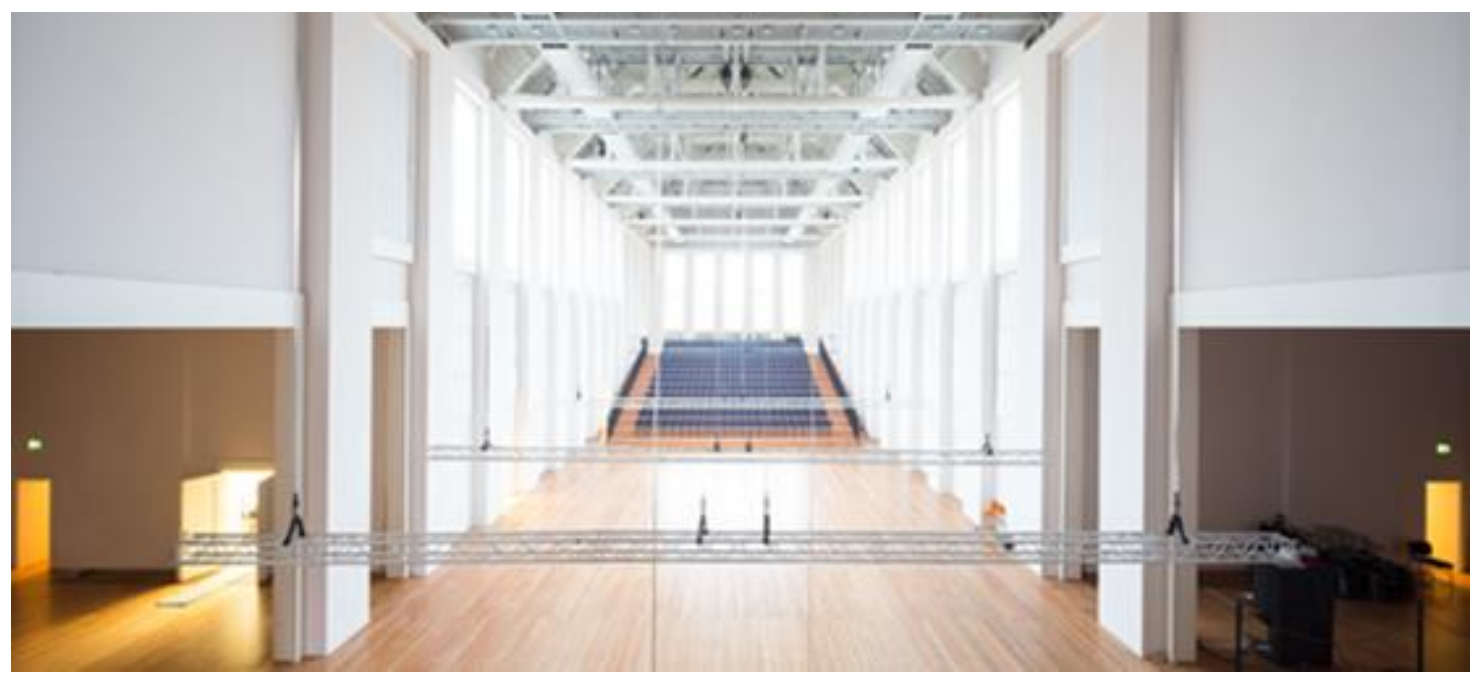

Figura 3. O Hellerau de Adolphe Appia, Dresden, Germany. 1911. Construído em 1911, foi um importante centro no início do teatro moderno até a ascensão do partido nazista. Cortesia do fotógrafo Marc Goodwin, 2014.

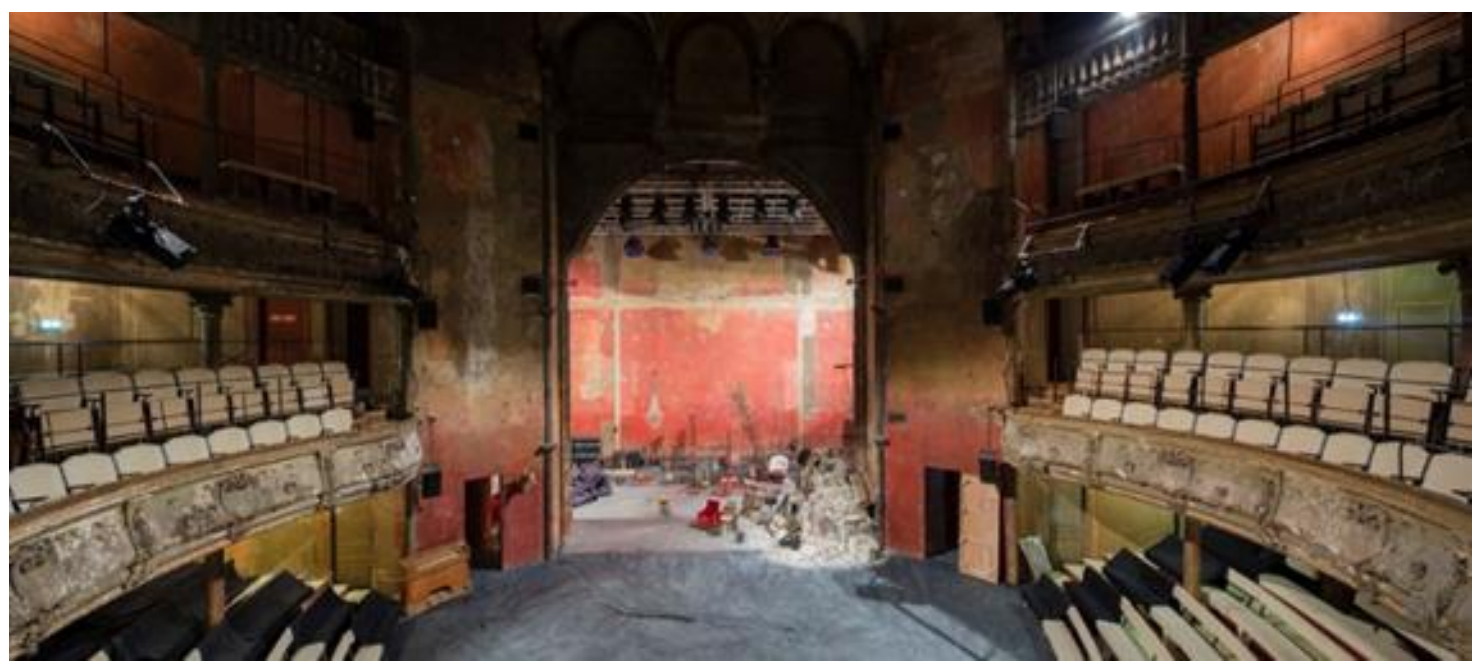


Figura 4. O Bouffes du Nord projetado por Louis-Marie Emile Leménil em 1876.

Peter Brook reabriu o teatro em 1974, e "com muito sucesso transformou a sala de espetáculos barroca em forma de U em um local dinâmico" (p. 87). Cortesia do fotógrafo Marc Goodwin, 2014.

No capítulo seguinte sobre "Espaço Abstrato", o foco é o Teatro Total do arquiteto Walter Gropius, projetado para o maestro e teórico Erwin Piscator e nunca construído - um projeto que, segundo Hannah, transformou o edifício teatral em uma máquina arquitetônica. Com base nas teorias da produção do espaço de Henry Lefèbvre (1991 [1974]), para ela, o arquétipo da arquitetura teatral do século XX propõe uma suposta homogeneidade do espaço abstrato modernista ao qual ela associa uma prática espacial reducionista que segue uma lógica funcional, apresentando neutralidade e transparência.

No entanto, o capítulo mais instigante é o quarto, intitulado "Espaço Abjeto - para a Arquitetura da Crueldade", no qual a autora confronta os desenhos do século XVIII de Piranesi, apresentando inúmeras perspectivas sobrepostas que subvertiam a perspectiva e a estrutura renascentista de um único ponto de fuga, com a linguagem do espaço proposta por Antonin Artaud em The Theatre and Its Double (1958 [1938]). O termo "espaço-abjeto" surgiu das teorias de Artaud e George Bataille, que demonstraram uma revolta física contra a arquitetura racionalista devido, principalmente, à ausência de uma relação harmoniosa com o corpo visceral e inconsciente, sinalizando o fracasso dos projetos utópicos, tanto na arquitetura quanto no teatro.

Um dos exemplos mais dramáticos é o parágrafo em que Hannah aponta para a brutalidade inerente aos espaços de reunião pública quando o Teatro Dubrovka de Moscou foi ocupado durante três dias pelos rebeldes chechenos, ilustrando como uma arquitetura de teatro tradicional fornecia um local ideal para "criar barricadas para aprisionar reféns".

Fica explícito no livro que uma arquitetura rígida e fechada com palco italiano não se adequa mais à contemporaneidade e não oferece proteção aos espectadores. Citando Solà Morales (1984), Hannah defende uma arquitetura de teatro mais efêmera, objetivando um caráter dinâmico e acontecimental. Ela enfatiza que quando a performance se tornou visceral, a arquitetura se tornou mais desencorpada. Ela também identifica o uso desse "espaçoabjeto" no projeto de Le Fresnoy (fig. 5), concebido pelo arquiteto Bernard Tschumi (1996), igualmente defensor do espaço-evento, entre os outros exemplos que ela analisa, inclusive o Teatro Oficina, projetado por Lina Bo Bardi e Edson Elito. 


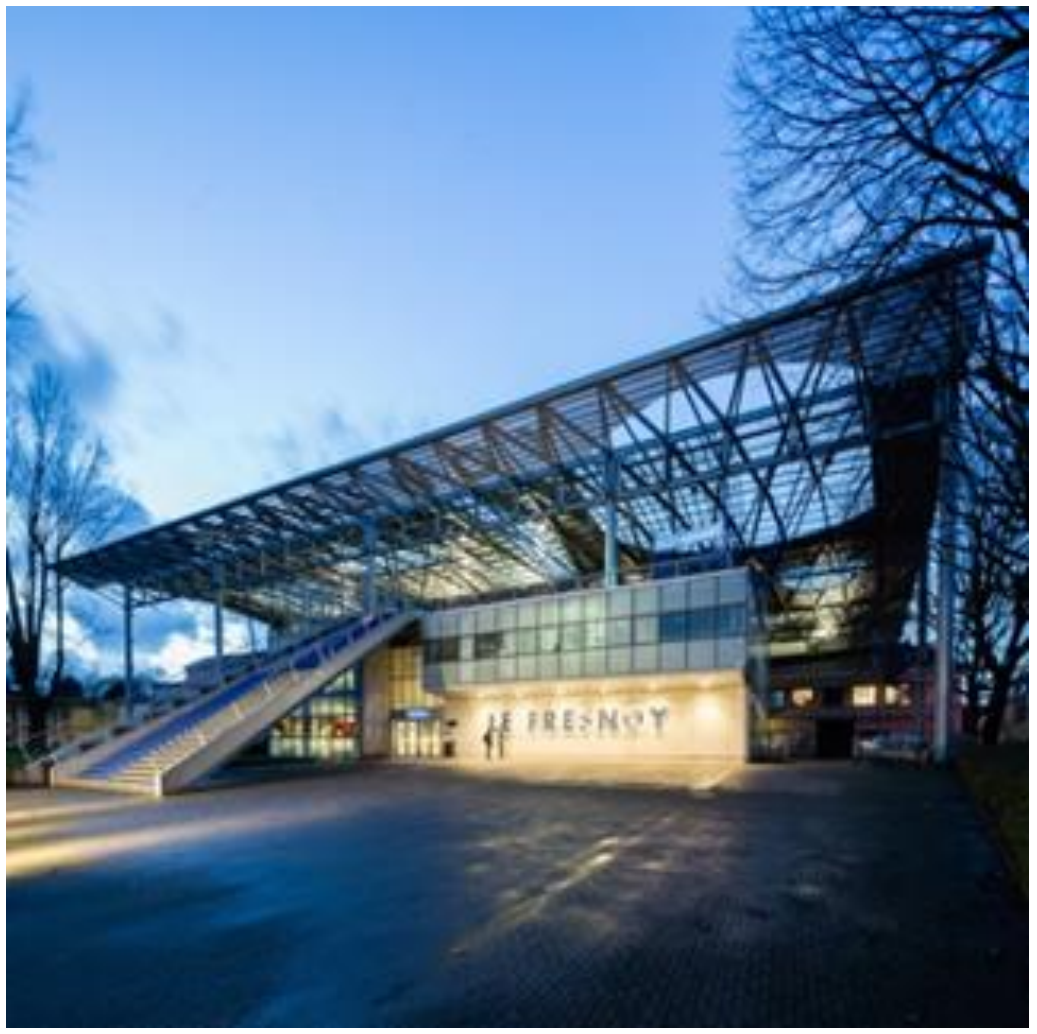

Fig. 5. Le Fresnoy - Studio national des arts contemporains, projetado por Bernard Tschumi. Tourcoing, França, 1997. O projeto estabeleceu "uma vertiginosa e fragmentada espacialidade para encontros criativos..." (p. 278). Cortesia do fotógrafo Marc Goodwin, 2014.

A natureza interdisciplinar do livro, envolvendo não apenas arquitetura, teorias teatrais, história da arte e, acima de tudo, filosofia, cenografia e dramaturgia, entre outras disciplinas, certamente atrairá leitores de diferentes áreas de estudo. Praticantes e teóricos dessas áreas e áreas afins devem se beneficiar da corajosa e ousada proposta deste livro em suas futuras investigações. A autora reavalia a defesa dos espaços não representativos pela vanguarda, aproveitando os campos específicos dos estudos da performance e dos estudos arquitetônicos para estabelecer uma teoria da "arquitetura performativa". Ela explica que essa noção do "acontecimental" emergiu das revoluções espaço-temporais na ciência, nas artes e na comunicação do século XX, por meio das quais a espacialização estática do espaço enfatizava o movimento, a relatividade e a duração.

Com base em diferentes fontes e teorias, Hannah mantém o foco de seu argumento e conduz o leitor ao longo dos capítulos em uma viagem provocativa e fascinante, lançando novas luzes sobre uma arquitetura teatral que funciona como um evento real.

Como cada vez mais escolas de artes cênicas e arquitetura têm criado cursos de pósgraduação, além de muitos cursos de graduação nessas áreas que já estão subdivididas em diferentes especialidades, os leitores que mais se beneficiarão dessa análise serão os universitários e acadêmicos dessas áreas. No entanto, como os subcampos se expandiram muito com as interrelações entre as diferentes áreas especialmente com a introdução dos 
estudos da performance e, por consequência, da antropologia, esta pesquisa ponderada é uma contribuição valiosa para o mundo acadêmico, e, também, para os profissionais das diferentes áreas abrangidas pelo presente livro.

\section{Referências}

ARTAUD, Antonin. The Theatre and Its Double. New York: Grove Weidenfeld, 1958. Tradução: Mary Caroline Richards.

CARLSON, Marvin. Places of Performance. The Semiotics of Theatre Architecture. Ithaca: Cornell University Press, 1989

CARLSON, Marvin. The Changing Places of Performance. Conferência apresentada no Second International Conference on Architecture, Theatre and Culture - Unirio, Rio de Janeiro, 2012.

HANNAH, Dorita, Event-Space: Theatre Architecture and the Historical Avant-Garde. London: Routledge, 2018.

LEVEBVRE, Henry. The Production of Space. Oxford: Blackwell, 1991 [1974]. Tradução: Donald Nicholson-Smith.

NIETZSCHE, Friedrich, The Birth of Tragedy. Oxford: Oxford University Press, 2008 [1872]. Tradução: Douglas Smith,

SOLÀ MORALES, Ignasi. Architectura Teatral en España, Madrid: MOPU, 1984.

TSCHUMI, Bernard. Architecture and Disjunction. Cambridge, MA: The MIT Press, 1996.

WILES, David. A Short History of Western Performance Space. Cambridge: Cambridge University Press, 2003. 